\title{
Konsep Penginjeksian Mata Kuliah Baru Pada Program Studi Pendidikan Teknik Elektro
}

\author{
Nadia Utari ${ }^{1,2^{*}}$ dan Riki Mukhaiyar ${ }^{2}$ \\ ${ }^{1}$ SMK Multi Mekanik Masmur Pekanbaru \\ ${ }^{1,2}$ Prodi Magister Pendidikan Teknologi dan Kejuruan, Fakultas Teknik, Universitas Negeri Padang \\ *Corresponding author, e-mail: nadia.utari79@gmail.com
}

\begin{abstract}
Abstrak - Pendidikan tinggi harus beradaptasi dengan perkembangan Ilmu Pengetahuan dan Teknologi, salah satu cara yang dapat dilakukan Perguruan Tinggi dengan melaksanakan pengayaan kurikulum. Pengayaan kurikulum dapat dilakukan dengan menambahkan mata kuliah baru. Artikel ini bertujuan untuk menemukan konsep penginjeksian mata kuliah baru, khususnya pada program studi Pendidikan Teknik Elektro Universitas Negeri Padang. Metode dalam penelitian ini menggunakan penelitian kualitatif pendekatan komparatif ex post facto. Karakteristik penelitian ini membandingkan dua kelompok berbeda, yaitu membandingkan kurikulum Universitas LPTK (Lembaga Pendidikan Tenaga Kependidikan) dan kurikulum Universitas Non-LPTK untuk mencari karakteristik kurikulum dalam mengiputkan mata kuliah yang berbeda dengan karakteristik pendidikan vokasi, tetapi sesuai dengan karakteristik pendidikan vokasi dalam mempertimbangkan penginputan mata kuliah yang selaras dengan karakteristik digital pada bidang studi pendidikan kejuruan. Kesesuaian karakteristik mata kuliah Image Processing dengan karakteristik kurikulum LPTK menghasilkan sebuah Rencana Pembelajaran Semester (RPS) mata kuliah Image Processing untuk dapat diterapkan pada program studi Pendidikan Teknik Elektro Universitas Negeri Padang.
\end{abstract}

Kata Kunci : Kurikulum, Pendidikan Vokasional, Image Processing

\begin{abstract}
Higher education must adapt to the advencement of Science and Technology, one of the ways that Universities can do by implementing curriculum enhancement. Curriculum enhancement can be done by adding new courses. This article aims to find the concept of injecting new subjects, especially in the Electrical Engineering Education study program, State University of Padang. The method in this study uses a qualitative research ex post facto comparative approach. The characteristics of this study compare two different groups, namely comparing the curriculum of the University of LPTK (Lembaga Pendidikan Tenaga Kependidikan) and the curriculum of the University of Non-LPTK to look for curriculum characteristics in covering different subjects with the characteristics of vocational education, but in accordance with the characteristics of vocational education in considering eye input lectures that are aligned with digital characteristics in the field of vocational education studies. The suitability of the characteristics of the Image Processing course with the characteristics of the LPTK curriculum results in a Semester Learning Plan for the Image Processing course to be applied to the Electrical Engineering Education study program in State University of Padang.
\end{abstract}

Keywords: Curriculum, Vocational Education, Image Processing

This is an open access article distributed under the Creative Commons 4.0

\section{Pendahuluan}

Kurikulum menduduki posisi paling signifikan dalam aktivitas pendidikan, karena kurikulum berhubungan dengan penentuan arah, isi dan proses aktivitas pendidikan, yang bermuara pada penentuan jenis dan kualifikasi output pendidikan tersebut. Tanpa adanya kurikulum yang tepat dan sesuai dalam aktivitas pembelajaran, maka akan sulit bagi perguruan tinggi untuk mencapai tujuan dan target pendidikan yang ingin dicapai. Menurut Peraturan Presiden Nomor 8 Tahun 2012 tantang Kerangka Kualifikasi Nasional Indonesia (KKNI). KKNI merupakan kerangka pengkualifikasian yang menyandingkan, menyetarakan, dan mengintegrasikan capaian pembelajaran. Oleh 
sebab itu, setiap Perguruan tinggi perlu berupaya menstimulasikan dan beradaptasi pada ketentuan yang telah diterbitkan tersebut. Ketentuan tersebut memberikan karakter atau kualitas output lulusan harus menguasai standar kompetensi lulusan yang bisa digunakan dan signifikan dengan lapangan pekerjaan yang tersedia, selain memiliki kompetensi utama, lulusan juga wajib memiliki kompetensi penunjang dan kompetensi lainnya (pelengkap), sehingga output Pendidikan Tinggi mempunyai daya kompetitif yang tinggi dan luas untuk menuju dunia kerja [1]. S1 Pendidikan Teknik Elektro Universitas Negeri Padang (UNP) merupakan penghasil sarjana pendidikan yang secara akademis mampu mengelaborasi diri dan beradaptasi dengan perkembangan dunia kerja,

engurangi mata kuliah. Bagi setiap perguruan tinggi termasuk UNP khususnya Pendidikan Teknik Elektro, evaluasi terhadap kurikulum secara berkala dan terencana merupakan suatu bentuk target dalam melaksanakan revisi terhadap kapasitas perguruan tinggi. Pengayaan dalam pengembangan kurikulum pada pendidikan tinggi adalah teknik untuk menyesuaikan perkembangan ilmu pengetahuan dan teknologi dalam mempersiapkan diri ke arah era Revolusi Industri 4.0. Revolusi Industri 4.0 dipersepsikan sebagai bentuk otomatisasi yang dilakukan oleh kecerdasan komputasi (artifitial intelligent), dalam bentuk algoritma komputer, guna meningkatkan keefektifitasan sebuah proses.

Keberhasilan reformasi penggunaan Image Processing telah menciptakan keefektifitasan diberbagai bidang. Sudah sepantasnya Pendidikan Teknik Elektro UNP mempertimbangkan untuk menyuntikkan subyek yang selaras dengan hal-hal tersebut, salah satu mata kuliah yang perlu dipertimbangkan adalah mata kuliah Image Processing dengan alasan banyak ditemukan implementasi dari mata kuliah Image Processing dalam kehidupan sehari-hari, misalnya pada photo editing, otomasi perkantoran, media, biometrik kedokteran (medis), entertainment, senjata militer dan banyak lainnya yang kini menggunakan ilmu pun non formal, perbankan, BUMN, wirausahawan bidang teknik elektro atau bidang lain yang relevan. Oleh karena hal tersebut, dalam memberikan kepuasaan pada stakeholders (pemangku kepentingan) lulusan dalam bidang tersebut, maka perlu diwadahi dengan kurikulum yang handal dengan menyelusuri kemajuan iptek, dan mencetak lulusan yang mempunyai keahlian selain bidang utama yang telah ditetapkan.

Pengayaan kurikulum dilakukan dengan penginputan mata kuliah Image Processing. masyarakat dan ilmu pengetahuan dibidang teknik elektro. Untuk meningkatakan relevansi Capaian Pembelajaran Lulusan kurikulum dengan lapangan kerja yang tersedia adalah dengan cara memaksimalkan kompetensi lulusan.

Kurikulum adalah input pokok dalam bidang pendidikan, diperlukan perbaikan dan reformasi pendidikan bidang kurikulum [2,3]. Pengayaan dalam pengembangan kurikulum merupakan suatu usaha ataupun sebuah aktivitas untuk mencari tahu dan memberikan keputusan bahwa program dalam pendidikan yang dijalani masih relevan atau tidak relevan dengan tujuan yang telah dicanangkan [4]. Pengayaan kurikulum dapat dilakukan dengan menambah atau $\mathrm{m}$

pengolahan gambar. Kurikulum merupakan desain pendidikan yang memiliki posisi yang sangat vital dalam semua aspek kegiatan pendidikan, jika kurikulum yang diberikan kepada mahasiswa sesuai dan berkualitas, maka secara langsung akan mempengaruhi lulusan. Berdasarkan konteks tersebut, maka Pendidikan Teknik Elektro UNP sepatutnya menelaah kembali kurikulumnya, agar mempunyai kurikulum yang kredibel dan memiliki daya saing untuk mencetak ouput (lulusan), serta mampu berdikari untuk menentukan kehidupan dimasa depan. Sesuai dengan visi, misi dan tujuan yang dicanangkan oleh program studi Pendidikan Teknik Elektro Universitas Negeri Padang bahwa lulusan dari program studi tersebut adalah untuk menjadi guru profesional pada bidang teknik kejuruanl [5], namun menurut survei peneliti melalui observasi dan wawancara banyaknya ditemukan lulusan dari program studi Pendidikan Vokasi Teknik Elektro bekerja selain dari bidang yang ditetapkan dalam visi program studi Pendidikan Teknik Elektro, yakni ada yang bekerja di industri, instalatir, arsitek listrik, bekerja di konsultan (mengitung biaya pemasangan listrik, dll), instruktur pelatihan kejuruan teknik elektro baik pada institusi formal mau

Image Processing merupakan salah satu mata kuliah pada kurikulum Non-LPTK S1 Teknik Elektro dalam memperbaiki dan memanipulasi suatu objek gambar, outputnya berupa gambar lain dalam bentuk 2D, 3D, dan multi dimensi. Image Processing adalah suatu ilmu pengetahuan dalam mendalami metode pengolahan citra, defenisi citra yang dijabarkan adalah foto maupun video, sedangkan mengolah gambar menggunakan komputer disebut dengan digital. Konsep dasar Image Processing merupakan implemantasi dari 
kapabilitas paca indera manusia kemudian disambungkan dengan kekuatan akal manusia untuk dilakukan pengolahan gambar digital tersebut. Image Processing saat ini sudah dikembangkan dan diaplikasikan dalam berbagai bentuk.

Dalam hal ini peneliti perlu dilakukan penelitian lebih lanjut tentang pengayaan kurikulum dengan memasukkan proses ilmiah pada program studi Pendidikan Teknik Elektro UNP dengan menambahkan mata kuliah Image Processing. Karakteristik penelitian ini untuk menemukan metode penginputan mata kuliah baru, yang berbeda dengan karakteristik pendidikan vokasi Pendidikan Teknik Elektro, tetapi sesuai dengan karakteristik pendidikan vokasi dalam mempertimbangkan penginputan mata kuliah yang selaras dengan karakteristik digital dalam bidang studi pendidikan kejuruan.

\section{METODA}

Dalam kajian ini penelitian menggunakan metode kualitatif pendekatan kausal komporatif $e x$ post facto (Gambar 1). Tujuan dari penelitian ini untuk mendapatkan suatu konsep penginjeksian dari kurikulum Non-LPTK ke kurikulum LPTK, dengan menguraikan masing-masing karakteristik kurikulum. Dalam hal ini peneliti akan membuat RPS mata kuliah Image Processing untuk program studi Pendidikan Vokasi Teknik Elektro yang sesuai dengan karaketristik digital pendidikan kejuruan LPTK.

Metode yang dikomparatifkan yaitu membandingkan empat kurikulum universitas Non-LPTK Teknik Elektro dan kurikulum universitas LPTK program studi Pendidikan Teknik Elektro untuk mencari karakteristik kurikulum dalam mengiputkan mata kuliah Image Processing. Peneliti mencari karakteristik kurikulum Non-LPTK yang berbeda dengan karakteristik kurikulum pendidikan vokasi, tetapi menyesuaikan dengan karakteristik pendidikan vokasi untuk mempertimbangkan penginputan mata kuliah Image Processing di Universitas LPTK. Ada empat Universitas Non-LPTK, yang dijadikan sebagai obyek penelitian yaitu Universitas Indonesia, Universitas Gajah Mada, Institut Teknologi Bandung dan Universitas Andalas. Universitas LPTK yang menjadi perbandingan yaitu Universitas Negeri Yogyakarta, Universitas Pendidikan Indonesia, Universitas Negeri Jakarta dan Universitas Negeri
Padang. Alasan peneliti menjadikan universitas ini sebagai objek perbandingan karena universitas ini menjadi benchmarking universitas Non-LPTK dan LPTK yang paling berkualitas di Indonesia.

\begin{tabular}{|c|c|}
\hline $\begin{array}{l}\text { Karakteristik kurikulum } \\
\text { LPTK Ditinjau dari Mata } \\
\text { Kuliah Mikroprosesor }\end{array}$ & $\begin{array}{l}\text { Karakteristik Kurikulum Non } \\
\text { LPTK Ditinjau dari Mata } \\
\text { Kuliah Image Processing }\end{array}$ \\
\hline \multicolumn{2}{|c|}{ Capaian Pembelajaran } \\
\hline $\begin{array}{l}\text { Karakteristik dari mata kuliah } \\
\text { Mikroprosesor mahasiswa } \\
\text { dapat memahami, menjelaskan, } \\
\text { dan menerapkan konsep mata } \\
\text { kuliah teknik terutama } \\
\text { dibidang pendidikan kejuruan. }\end{array}$ & $\begin{array}{l}\text { Karakteristik dari mata kuliah } \\
\text { image processing mahasiswa } \\
\text { dapat memahami, mendesain, } \\
\text { menganilisis, } \\
\text { mengaplikasikan konsep } \\
\text { mata kuliah yang di ampu }\end{array}$ \\
\hline \multicolumn{2}{|c|}{ Rumusan Profil Lulusan } \\
\hline $\begin{array}{l}\text { Menghasilkan pendidik } \\
\text { kejuruan seperti sekolah } \\
\text { kejuruan, pusat pelatihan } \\
\text { kejuruan, perusahaan, dan } \\
\text { lapangan kerja industri } \\
\text { lainnya. }\end{array}$ & $\begin{array}{lr}\text { Menghasilkan } & \text { lulusan } \\
\text { sarjana yang } & \text { memiliki } \\
\text { keahlian luas } & \text { dibidang } \\
\text { teknik elektro. } & \end{array}$ \\
\hline
\end{tabular}

Karakteristik mata kuliah Image Processing sesuai atau tidak sesuai di universitas LPTK

Gambar 1. Diagram Metodologi Penelitian

Peneliti membandingkan masing-masing kurikulum Universitas Non-LPTK untuk mendapatkan karakteristik mata kuliah Image Processsing di bidang Teknik Elektro yang memiliki komposisi mata kuliah yang terdiri dari kelompok mata kuliah wajib dan mata kuliah pilihan. Peneliti meninjau mata kuliah Image Processing universitas Non-LPTK melalui silabus dan RPS, sehingga peneliti menemukan karakteristik mata kuliah tersebut sesuai atau tidak sesuai, jika diinputkan ke Universitas LPTK khususnya Program Studi Pendidikan Teknik Elektro UNP.

Setelah ditemukan kesusuaian karakteristik dengan kurikulum LPTK, peneliti akan membuat RPS mata kuliah Image Processing. RPS ini akan peneliti validasi oleh beberapa ahli pada bidang pengembangan kurikulum, ahli pada bidang isi untuk mata kuliah Image Processing, dan ahli tata bahasa. Hasil analisis data validatas dari para ahli dalam rangka perbaikan RPS Image Processing yang akan diterapkan pada kurikulum Pendidikan Teknik Elektro. Peneliti menganalisis hasil judgement expert menggunakan koefisien validitas Aiken's V. Skor mentah dari validator 
tersebut dianalisa memakai rumus formula dari Aiken's V. Rentang angka V yang diperoleh antar 0 sampai 1,00 . Untuk kategori rentang yang $\geq$ 0,667 dinterprestasikan dalam koefisien yang cukup tinggi, sehingga bisa dikelompokkan dengan kategori valid [14]. Untuk menentukan tingkat kevalidan dapat dideskripsikan melalui kriteria pada Tabel 1.

Tabel 1. Kriteria koefisien validitas Aiken's V.

\begin{tabular}{|c|c|}
\hline Rata-Rata Skor & Kriteria Penafsiran \\
\hline$>0,67-1,0$ & valid \\
\hline$<0,66$ & Tidak Valid \\
\hline
\end{tabular}

\section{A. Kurikulum Pendidikan Tinggi}

Kurikulum merupakan segenap pengalaman yang didapatkan mahasiswa saat melakukan kegiatan pembelajaran yang digunakan untuk mendapatkan tujuan yang telah ditetapkan didesain dalam wujud teori dan kajian profesional pada masa lampau dan saat ini [6]. Kurikulum merupakan program pendidikan yang dirancang dan direncanakan secara sistematis sebagai pedoman dalam kegiatan pembelajaran bagi dosen dan mahasiswa untuk mecapai tujuan pendidikan [7]. Kurikulum pendidikan tinggi merupakan suatu rencana program pembelajaran dalam mencapai suatu target proses pembelajaran pada suatu lembaga pendidikan yang dijadikan acuan oleh dosen dan mahasiswa, oleh sebab itu kurikulum menduduki posisi penting dalam membentuk pembelajaran yang berkualitas dan bermutu. Pendidikan yang berkualitas akan menghasilkan lulusan seiring dengan harapan masyarakat seperti kualitas personal, moralitas, pengetahuan, dan kompetensi kerja yang merupakan syarat mutlak dalam penyesuaian secaraglobal dan berkelanjutan berkelanjutan [8]. Kurikulum pendidikan tinggi yang berkualitas membutuhkan satu prosedur yang jelas, strategi, dan kolaborasi dengan pemangku kepentingan secara terus menerus agar Perguruan Tinggi dapat mengikuti perkembangan Ilmu Pengetahuan dan Teknologi yang berkembang dewasa ini.

\section{B. Kerangka Kualifikasi Nasional Indonesia (KKNI)}

Dalam Peraturan Menteri Pendidikan dan Kebudayaan Nomor 72 Tahun 2003, KKNI dalam Pendidikan Tinggi adalah suatu bentuk stratifikasi kompetensi yang menyandingkan, menyetarakan dan mengintegrasikan capaian pembelajaran [9]. KKNI dibentuk berdasarkan atas kepentingan dan tujuan khusus untuk menyeimbangi sistem pendidikan dan sistem karir di dunia kerja. KKNI didisain untuk menyesuaikan sekaligus menyetarakan dengan sistem pendidikan yang berkembang di negara lain. Dapat didefenisikan bahwa kurikulum yang mengacu pada KKNI merupakan kurikulum yang dikembangkan dengan bentuk penjenjangan kualifikasi sebagai acuan minimal untuk memberikan pengakuan kompetensi kerja yang sesuai dengan struktur pekerjaan diberbagai sektor pekerjaan. Tingkatan kualifikasi pada KKNI dibentuk secara konkret dengan beban ilmu, pengetahuan, keahlian dan keterampilan. Sifat dari susunan unsur-unsur dalam deskriptor generik KKNI pada setiap jenjang kualifikasi tersebut sifatnya fleksibel, artinya Capaian Pembelajaran (CP) yang setara mempunyai keterampilan (skills) lebih dominan dibanding dengan keilmuan (science) dan pengetahuannya (knowledge), tatapi, tetap diberi pengakuan penjenjangan kualifikasi yang setara.

\section{Pengembangan Kurikulum}

Pengembangan kurikulum pada dasarnya merupakan prosedur penyusunan pertimbangan hasil pemikiran untuk membentuk kurikulum sebagai petunjuk dalam melaksanakan aktivitas pembelajaran. Pengembangan kurikulum biasanya linier dengan permintaan yang disyaratkan oleh stakeholder, agar lulusan program studi Pendidikan Teknik Elektro dapat diterima sesuai dengan kebutuhan pemangku kepentingan lulusan. Prosedur pengembangan kurikulum berhubungan dengan pemilihan dan penyusunan komponen kurikulum dalam aktivitas pembelajaran yang dilakukan, misalnya, pemilihan waktu, perancangan kurikulum, detail rincian target yang jadi pertimbangan, mata kuliah, aktivitas pembelajaran, sumber pembelajaran dan evaluasi dalam aktivitas pembelajaran di perguruan tinggi [10]. Kompilasi dan pengembangan kurikulum tidak dapat dikembangkan dengan gegabah, pondasi yang kuatdibutuhkan agar dapat digunakan sebagai landasan dalam melaksanakan proses pelaksanaan pendidikan, sehingga kurikulum dapat memudahkan pelaksanaan pendidikan dalam mencapai tujuan pembelajaran yang telah ditetapkan dan capaian pembelajaran yang lebih efektif dan efisien [11]. Agar kurikulum dapat sesuai dengan kebutuhan dewasa ini, dibutuhkan rekonstruksi dan reformasi kurikulum

\section{Pengolahan Citra (Image Processing)}

Pengolahan citra berarti megupayakan sebuah citra untuk dijadikan citra lain yang lebih komplet, dengan prosedur untuk menghasilkan output 
berupa citra yang dikehendaki [12]. Image processing merupakan suatu teknik yang dipakai untuk mengelola sebuah gambar dengan cara memanipulasi gambar menjadi suatu data yang dapat digunakan [13]. Berkembangnya teknik pengolahan citra digital dipicu oleh tujuan untuk membantu hidup manusia menjadi lebih mudah. Salah satu kemudahannya adalah membantu manusia dalam menginterprestasikan objek yang tertangkap kamera menggunakan teknik peningkatan kualitas citra. Selain itu, pengolahan citra digtal digunakan juga sebagai pengindra mesin otomatis. Perkembangan ini terbantu dengan perkembangan dunia teknologi khususnya komputer yang meningkat sangat cepat terutama segi kecepatan proses dan memori penyimpanan.

Pengolahan citra terus berkembang, perkembangan ini diringi dengan peralatanperalatan pendukung pengolahan citra, maka penggunaan penggunan Image Processing menjadi lebih beragam. Melalui pengolahan citra, fungsi sensor pengolahan pada manusia diharapkan dapat digantikan dengan sensor penglihatan buatan (kamera). Kecepatan proses komputer yang meningkat memungkin proses citra digital dilakukan secara realtime . Demikian juga perkembangan memori memungkinkan citra analog dapat dikodekan menjadi citra warna digital yang mendekati warna aslinya.

\section{HASIL DAN PEMBAHASAN}

Peneliti menggunakan empat universitas non LPTK, yaitu pada Universitas Indonesia (UI), Universitas Gajah Mada (UGM), Institut Teknologi Bandung (ITB) dan Universitas Andalas (UNAND) dalam membandingkan keempat kurikulum universitas Non LPTK tersebut sebagai objek komparatif dengan program studi yang sama dan mata kuliah yang sama. Kurikulum program studi S1 Non LPTK program studi Teknik Elektro memiliki komposisi mata kuliah yang sama, terdiri dari kelompok mata kuliah umum dan mata kuliah teknik. Untuk menemukan karakteristik kurikulum universitas non LPTK, peneliti meninjau karakteristiknya dari mata kuliah Pengolahan Citra (Image Processing). Berdasarkan ulasan yang ditemukan pada kurikulum program studi S1 Teknik Elektro di UI, UGM, ITB dan UNAND pada mata kuliah Pengolahan Citra (Image Processing) merupakan salah satu kelompok mata kuliah teknik. Peneliti meninjau karakteristik mata kuliah Pengolahan Citra (Image Processing) melalui RPS universitas non LPTK tersebut. Capaian pembelajaran mata kuliah Image Processing pada universitas Non LPTK yaitu: mahasiswa dapat memahami, menjelaskan, menganalisis, dan menerapkan teori yang diperoleh dalam pengolahan citra, sehingga diharapkan lulusan teknik dapat merancang, memecahkan masalah dan menerapkan pengetahuan dalam bidang teknik elektro. Capaian pembelajaran universitas LPTK dapat dilihat pada tabel 2 .

Tabel 2. Karakteristik Kurikulum Non-LPTK

\begin{tabular}{|c|c|c|c|c|}
\hline Indikator & UI & UGM & ITB & UNAND \\
\hline $\begin{array}{l}\text { Capaian } \\
\text { Pembela } \\
\text { jaran }\end{array}$ & $\begin{array}{l}\text { Dapat } \\
\text { memahami, } \\
\text { menjelaskan } \\
\text { dan } \\
\text { menganalisis } \\
\text { konsep dasar } \\
\text { pemrosesan } \\
\text { gambar } \\
\text { saintifik }\end{array}$ & $\begin{array}{l}\text { Dapat } \\
\text { menganalisis } \\
\text { dan } \\
\text { menerapkan } \\
\text { ilmu } \\
\text { pemprosesan } \\
\text { gambar }\end{array}$ & $\begin{array}{l}\text { Dapat } \\
\text { memahami, } \\
\text { mengenalisis } \\
\text { dan } \\
\text { menerapkan } \\
\text { ilmu } \\
\text { pemprosesan } \\
\text { gambar }\end{array}$ & $\begin{array}{l}\text { Dapat } \\
\text { memahami, } \\
\text { menjelaskan } \\
\text { dan } \\
\text { menganalisis } \\
\text { konsep } \\
\text { dasar } \\
\text { pemrosesan } \\
\text { gambar }\end{array}$ \\
\hline
\end{tabular}

Berdasarkan tabel 2, sesuai dengan prestasi lulusan universitas Non LPTK berdasarkan rumusan profil lulusan Pendidikan Tinggi, dalam menghasilkan lulusan yang mampu memahami, merancang dan mengaplikasikan pengetahuan, sikap, keterampilan, kompetensi, dan akumulasi pengalaman kerja bidang teknik elektro, sebagai insinyur dalam dunia industri, sebagai intelektual dan teknokrat, dan sebagai wirausahawan yang mampu berkomunikasi baik lisan maupun tulisan [15]. Dari rumusan Profil Lulusan Teknik Elektro ini yang menjadi penciri unggulan yang memiliki karakteristik yang spesifik, yang menjadikan Teknik Elektro berbeda.

Selanjutnya peneliti membandingkan empat Universitas LPTK yaitu: Universitas Pendidikan Indonesia (UPI), Univeristas Negeri Yogyakarta (UNY), Universitas Negeri Jakarta (UNJ), dan Universitas Negeri Padang (UNP). Dalam kurikulum universitas LPTK pada program studi Pendidikan Teknik Elektro, yaitu UPI, UNY, UNJ dan UNP memiliki komposisi subjek terdiri dari kelompok mata kuliah umum, mata kuliah teknik, dan mata kuliah keterampilan profesional. Peneliti memeriksa kurikulum universitas LPTK tersebut dengan menemukan karakteristiknya dari komposisi subjek mata kuliah teknik, peneliti akan meninjau capaian pembelajaran learning outcome dari mata kuliah Sistem Mikroprosesor dari masing-masing universitas LPTK tersebut. Peneliti memeriksa mata kuliah keteknikan melalui RPS dari Universitas Pendidikan Indonesia, Univeristas Negeri Yogyakarta, Universitas Negeri Jakarta, dan Universitas 
Negeri Padang. Peneliti menemukan bahwa mata kuliah keteknikan universitas LPTK memiliki capaian pembelajaran, yaitu untuk dapat menjelaskan dan memahami teori-teori mata kuliah keteknikan. Sesuai dengan rumusan profil lulusan Universitas LPTK berdasarkan capaian standar Pendidikan Tinggi, dalam menghasilkan lulusan yang kompeten untuk menjadi guru profesional dengan menguasai kemampuan teknik dan pedagogi kejuruan secara keseluruhan, mampu dalam dunia industri, mampu menjadi berwirausaha, bekerja dengan relevansi sesuai bidang keilmuannya dan mampu berkomunikasi baik lisan maupun tulisan [16]. Peneliti mengambil subjek perbandingan dari mata kuliah keteknikan dengan alasan demi mengeliminasi keraguan terhadap karakteritik output hanya berorientasi sebagai pendidik, dan hasilnya keluarannya akan hasilnya akan mengendurkan capaian terhadap kemampuan menguasai materi ilmu pengetahuan teknik yang diajarkan. Agar semua lulusan menguasai disiplin ilmunya bidang teknik elektro dengan baik. Sehingga lulusan LPTK mempunyai persiapan dalam meguasai keterampilan yang memadai dan cakap untuk bersaing dengan di dunia luar sesuai dengan keahlian yang dimiliki [17]. Capaian Pembelajaran universitas LPTK dapat dilihat pada tabel 3.

Tabel 3. Karakteristik Kurikulum LPTK

\begin{tabular}{|c|c|c|c|c|}
\hline Indikator & UI & UGM & ITB & UNAND \\
\hline $\begin{array}{l}\text { Capaian } \\
\text { Pembela } \\
\text { jaran }\end{array}$ & $\begin{array}{l}\text { Dapat } \\
\text { memahami } \\
\text { dan } \\
\text { menerapkan } \\
\text { konsep } \\
\text { dasar dari } \\
\text { mata kuliah } \\
\text { teknik }\end{array}$ & $\begin{array}{l}\text { Dapat } \\
\text { memahami } \\
\text { dan } \\
\text { menjelaskan } \\
\text { konsep } \\
\text { dasar dari } \\
\text { mata kuliah } \\
\text { teknik }\end{array}$ & $\begin{array}{l}\text { Dapat } \\
\text { memahami } \\
\text { dan } \\
\text { menerapkan } \\
\text { konsep dasar } \\
\text { dari mata } \\
\text { kuliah teknik }\end{array}$ & $\begin{array}{l}\text { Dapat } \\
\text { memahami, } \\
\text { menjelaskan, } \\
\text { dan } \\
\text { menerapkan } \\
\text { konsep dasar } \\
\text { dari mata } \\
\text { kuliah teknik }\end{array}$ \\
\hline
\end{tabular}

Berdasarkan tabel 3, hasil penelitian yang telah peneliti temukan dari pemeriksaan kurikulum tersebut ditemukan capaian profil lulusan dari universitas LPTK dan Non LPTK berbeda, tetapi dalam capaian pembelajran mata kuliah Image Processing terdapat kesesuaian dengan karakteristik kurikulum pendidikan kejuruan, khususnya pada program studi Pendidikan Teknik Elektro Universitas Negeri Padang. Dalam temuan penelitian, peneliti mendapatkan capaian profil lulusan gambaran kurikulum universitas NonLPTK dan kurikulum universitas LPTK sehingga, peneliti dapat merangkum perbedaan dua karakteristik kurikulum masing-masing universitas tersebut. Perbedaan karakteristik tersebut dapat dilihat pada tabel 4.
Berdasarkan tabel 4, dalam pembahasan ini peneliti melakukan studi pengayaan kurikulum dalam mengiputkan mata kuliah Image Processing pada kurikulum program studi Pendidikan Teknik Elektro di Universitas Negeri Padang.

Tabel 4. Perbandingan Capaian Profil Lulusan Universitas Non LPTK dan LPTK

\begin{tabular}{|l|lr|l|}
\hline Indikator & \multicolumn{2}{|c|}{ Non-LPTK } & \multicolumn{2}{c|}{ LPTK } \\
\hline Capaian & Menghasilkan lulusan & Menghasilkan \\
Profil & sarjana yang memiliki & pendidik kejuruan \\
Lulusan & keahlian yang luas & pada berbagai bidang \\
& sehingga & mereka & yang membutuhkan \\
& memiliki kompetensi & pendidik, seperti \\
& dibidang & teknik & sekolah kejuruan, \\
& elektro & pusat pelatihan \\
& & kejuruan, perusahaan, \\
& & dan lapangan kerja \\
& & & industri lainnya. \\
& &
\end{tabular}

Penelitian ini memeriksa karakteristik kurikulum universitas LPTK dengan meninjau kurikulum universitas Non-LPTK melalui RPS masing-masing universitas, kurikulum yang ditinjau adalah mata kuliah Image Processing yang merupakan mata kuliah dalam struktur kurikulum universitas Non-LPTK dan mata kuliah Mikroprosesor yang merupakan mata kuliah dalam struktur kurikulum universitas LPTK. Dari data hasil pengamatan penelitian menunjukkan bahwa karakteristik kurikulum Non-LPTK pada mata kuliah Image Processing menunjukkan kesuaian dengan karakteristik kurikulum LPTK khususnya program studi Pendidikan Teknik Elektro. Metode komparatif yang dibandingkan pada kurikulum Non-LPTK melalui RPS cakupan materi yang dibahas yaitu: prinsip gambar digital, karakteristik gambar digital, dan metode peningkatan kualitas gambar. Dalam hal ini diharapkan mahasiswa mampu menjelaskan, memahami, dan menganalisis teori ilmiah tentang mata kuliah Image Processing, hal ini senanda dengan karakteristik kurikulum LPTK. Karakteristik mata kuliah Image Processing mampu menyimbangi kurikulum LPTK untuk memenuhi kebutuhan pendidikan vokasi yang dibutuhkan dalam mengikuti perkembangan teknologi saat ini.

Setelah karakteristik mata kuliah Image Processing ditemukan peneliti membuat RPS untuk dimasukkan pada program studi Pendidikan Vokasi Teknik Elektro yang terlebih dahulu divalidasi oleh beberapa ahli, yaitu: ahli pada bidang pengembangan kurikulum, ahli pada bidang kajian image processing, dan ahli dari 
aspek bahasa RPS yang digunakan. Aspek yang akan ditinjau adalah aspek format, isi, bahasa dan waktu pada RPS mata kuliah Image Processing. Tabel 5. Hasil Validasi RPS dari aspek isi RPS

\begin{tabular}{|c|c|c|c|c|c|}
\hline \multirow{2}{*}{ No } & \multicolumn{3}{|c|}{ Validator } & \multirow{2}{*}{$\mathrm{V}=\sum_{1)]} s /[n(c-$} & \multirow{2}{*}{ Kriteria } \\
\hline & V1 & V2 & V3 & & \\
\hline 1 & 4 & 5 & 5 & 0,92 & Valid \\
\hline 2 & 4 & 5 & 5 & 0,92 & Valid \\
\hline 3 & 4 & 4 & 5 & 0,83 & Valid \\
\hline 4 & 5 & 4 & 4 & 0,83 & Valid \\
\hline 5 & 4 & 4 & 5 & 0,83 & Valid \\
\hline 6 & 5 & 4 & 5 & 0,92 & Valid \\
\hline \multicolumn{4}{|c|}{ Rata-rata } & 0,88 & Valid \\
\hline \multicolumn{4}{|c|}{ Persentase } & \multicolumn{2}{|c|}{$88 \%$} \\
\hline
\end{tabular}

Berdasarkan tabel 5, validasi aspek isi RPS merupakan validasi yang dilakukan terhadap temuan konsep dari penginjeksian mata kuliah baru pada program studi Pendidikan Teknik Elektro yang dihasilkan dan divalidasi oleh ahli/pakar sebanyak 3 (tiga) orang validator. Rangkuman hasil validasi RPS dari aspek isi telah dinilai oleh validator 1 , validator 2 , dan validator 3 memberikan rata-rata penilaian terhadap isi RPS sebesar 0,88 yang tergolong dalam kategori Valid.

Tabel 6. Hasil Validasi RPS dari aspek format RPS

\begin{tabular}{|c|c|c|c|c|c|}
\hline \multirow{2}{*}{ No } & \multicolumn{3}{|c|}{ Validator } & \multirow{2}{*}{$\mathrm{V}=\sum \mathrm{s} /[n(c-1)]$} & \multirow[b]{2}{*}{ Kriteria } \\
\hline & V1 & V2 & V3 & & \\
\hline 1 & 5 & 5 & 5 & 1 & Valid \\
\hline 2 & 5 & 4 & 4 & 0,83 & Valid \\
\hline \multicolumn{4}{|c|}{ Rata-rata } & 0,92 & Valid \\
\hline & & tase & & \multicolumn{2}{|c|}{$92 \%$} \\
\hline
\end{tabular}

Bedasarkan tabel 6, validasi aspek format RPS merupakan validasi yang dilakukan terhadap format RPS yang dihasilkan dan divalidasi oleh ahli/pakar sebanyak 3 (tiga) orang validator. Rangkuman hasil validasi RPS yang telah dinilai oleh validator 1 , validator 2 , dan validator 3 memberikan rata-rata penilaian RPS sebesar 0,92 yang tergolong dalam kategori Valid.

Tabel 7. Hasil Validasi RPS dari aspek waktu RPS

\begin{tabular}{|c|c|c|c|c|c|}
\hline \multirow{2}{*}{ No } & \multicolumn{3}{|c|}{ Validator } & V $=\sum_{\mathbf{1}}^{\boldsymbol{s}} /[\boldsymbol{n}(\boldsymbol{c}-$ & \multirow{2}{*}{ Kriteria } \\
\cline { 2 - 4 } & $\mathbf{V 1}$ & $\mathbf{V 2}$ & $\mathbf{V 3}$ & 0,92 & Valid \\
\hline 1 & 4 & 4 & 4 & 0,83 & Valid \\
\hline 2 & 5 & 4 & 5 & 0,92 & Valid \\
\hline 3 & 5 & 5 & 5 & 0,89 & Valid \\
\hline \multicolumn{3}{|c|}{ Rata-rata } & \multicolumn{3}{c|}{$89 \%$} \\
\hline \multicolumn{3}{|c|}{ Persantase } & \\
\hline
\end{tabular}

Berdasarkan tabel 7, validasi aspek waktu yang terdapat pada RPS didapatkan bahwa rangkuman hasil validasi oleh validator 1 , validator 2 , dan validator 3 memberikan rata-rata penilaian sebesar 0,89 yang tergolong dalam kategori Valid.

Tabel 8. Hasil Validasi RPS dari aspek bahasa RPS

\begin{tabular}{|c|c|c|c|c|c|}
\hline \multirow{2}{*}{ No } & \multicolumn{3}{|c|}{ Validator } & V $=\sum \boldsymbol{s} /[\boldsymbol{n}(\boldsymbol{c}-$ & \multirow{2}{*}{ Kriteria } \\
\cline { 2 - 4 } & $\mathbf{V 1}$ & $\mathbf{V 2}$ & $\mathbf{V 3}$ & $\mathbf{1})$ & \\
\hline 1 & 4 & 5 & 4 & 0,83 & Valid \\
\hline 2 & 5 & 4 & 4 & 0,83 & Valid \\
\hline 3 & 5 & 4 & 5 & 0,92 & Valid \\
\hline 4 & 5 & 5 & 5 & 1 & Valid \\
\hline \multicolumn{3}{|c|}{ Rata-rata } & 0,90 & Valid \\
\hline \multicolumn{3}{|c|}{ Persentase } & \multicolumn{3}{c}{$90 \%$} \\
\hline
\end{tabular}

Berdasarkan tabel 8, validasi aspek bahasa yang terdapat pada RPS yang telah didapatkan bahwa rangkuman hasil validasi oleh validator 1 , validator 2 , dan validator 3 memberikan rata-rata penilaian sebesar 0,90 yang tergolong dalam kategori Valid.

Dari penilaian validitas Rencana Pembelajaran Semester mata kuliah Image Processing yang divalidasi dari aspek format, isi, bahasa dan waktu yang dilakukan oleh dosen pakar pengembangan kurikulum, isi kurikulum, dan tata bahasa dapat direpresentasikan secara keseluruhan pada Gambar 2.

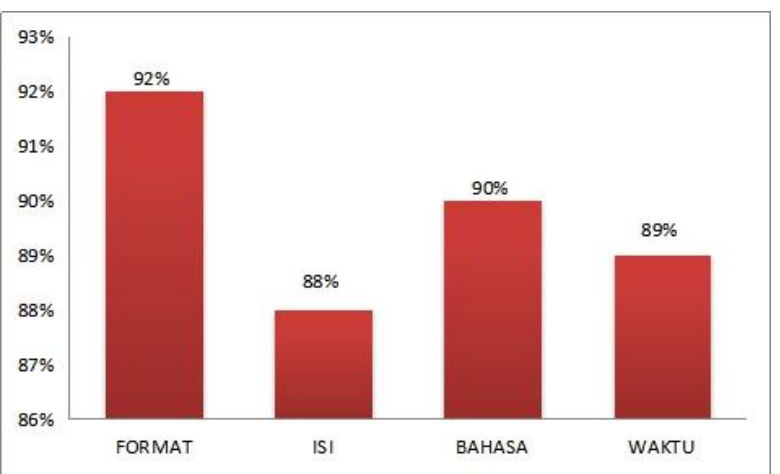

Gambar 2. Persentase hasil penilaian validator

Persentase keseluhan hasil penilaian validator dapat dilihat pada gambar 2, dari rata-rata keseluruhan hasil penelitian dalam konsep penginjeksian mata kuliah baru pada program studi Pendidikan Teknik Elektro Universitas Negeri Padang dapat dilihat dari aspek format persentasenya kevalidannya $92 \%$, pada aspek isi terdapat pesentase kevalidan $88 \%$, dilihat dari aspek bahasa terdapat persentasenya kevalidan $90 \%$ dan aspek waktu terdapat persentase kevalidannya $89 \%$.

Berdasarkan penilaian dari beberapa ahli/pakar dalam pengembangan kurikulum, isi kurikulum mata kuliah Image Processing, dan tata bahasa Rencana Pembelajaran Semester mata kuliah 
Image Processing memperoleh nilai rata-rata 0,90, dengan nilai persentase $90 \%$. Jika rentang angka $\mathrm{V}$ yang didapat $\geq 0,667$ dapat ditafsirkan sebagai nilai yang cukup tinggi, sehingga validitas dapat dikelompokkan dalam kategori "valid".

Tabel 9. Hasil Validasi RPS secara keseluruhan

\begin{tabular}{|c|l|l|l|}
\hline No & \multicolumn{1}{|c|}{ Aspek } & \multicolumn{1}{|c|}{ Rat-rata } & Kriteria \\
\hline 1 & Aspek Format & 0,92 & Valid \\
\hline 2 & Aspek Isi & 0,88 & Valid \\
\hline 3 & Aspek Bahasa & 0,90 & Valid \\
\hline 4 & Aspek Waktu & 0,89 & Valid \\
\hline Rata-rata & 0,90 & Valid \\
\hline \multicolumn{2}{|c|}{ Persetase } & \multicolumn{2}{c|}{$90 \%$} \\
\hline
\end{tabular}

\section{KESIMPULAN}

Dari hasil dan pembahasan dapat disimpulkan bahwa, setelah peneliti mengkaji karakteristik kurikulum dua kelompok universitas yang berbeda yaitu kelompok universitas LPTK dan kelompok universitas Non LPTK, peneliti membuat RPS mata kuliah Image Processing yang disesuaikan dengan karakteristik digital kurikulum Pendidikan Teknologi Kejuruan khususnya program studi Pendidikan Teknik Elektro di Universitas Negeri Padang. Setelah membuat RPS mata kuliah Image Processing peneliti mengujikan validitas RPS mata kuliah Image Processing ke validator yang berada di lingkungan Universitas Negeri Padang. Peneliti telah membuat RPS mata kuliah Image Processing untuk program studi Pendidikan Vokasi Teknik Elektro Universitas Negeri Padang. Persetanse validitas RPS mata kuliah Image Processing yang telah diujikan ke validator yang berada di lingkungan Universitas Negeri Padang dinyatakan valid. Validitas RPS dilihat dari dari empat aspek, yaitu: aspek format, aspek isi, aspek bahasa, dan aspek waktu. Untuk hasil validasi aspek isi dinyatakan valid dapat dilihat pada tabel 5, dari aspek format dinyatakan valid dapat dilihat pada tabel 6 , hasil validasi aspek waktu dinyatakan valid dapat dilihat pada tabel 7 , dan dilihat dari aspek bahasa dinyatakan valid dapat dilihat pada tabel 8. Sebagai konseptor dan pengagas ide awal, paper ini diharapkan dapat menjadi sebuah illustrator pembuka bagi metode pengayaan dalam pengembangan kurikulum bagi universitas LPTK berikutnya, khususnya untuk program studi Pendidikan Teknik Elektro.

\section{DAFTAR Pustaka}

[1] Syarifuddin. "Laporan Penelitian. Model Penerapan Kualifikasi Kurikulum Nasional
Indonesia (KKNI) Sebagai Penguatan Mutu Program Studi Pariwisata dan pendidikan Bahasa Inggris Fakultas Sastra dan Budaya Universitas Negeri Gorontalo," Gorontalo: Fakultas Sastra dan Budaya Universitas Negeri Gorontalo. 2013.

[2] Collin N Power. "Improving The Effectiveness of Curriculum Development and Reform In Africa," A Handbook for Curriculum Planners. 1999.

[3] Wardina, Unung Vera, Nizwardi Jalinus, and Lise Asnur. "Kurikulum Pendidikan Vokasi Pada Era Revolusi Industri 4.0," Jurnal Pendidikan: pp 82-90. 2019.

[4] Busro, Muhammad. "Perencanaan dan Pengembangan Kurikulum," Yogyakarta: Media Akademi. 2017.

[5] Mukhaiyar, Mukhaiyar., Utari S., and Mukhaiyar, R., "English as a Second Language for an International Nursery Student in United Kingdom," pp 107-114. 2016.

[6] Rusdi, Rino. "Konsep Pengembangan Kurikulum. UNP Press. Sutrisno dan Suyadi. 2016. Desain Kurikulum Perguruan Tinggi Mengacu Kerangka Kualifikasi Nasional Indonesia," Bandung: PT. Remaja Rosdakarya Offset. 2012.

[7] Dakir. "Perencanaan dan Pengembangan Kurikulum," Jakarta: PT. Rineka Cipta. 2004.

[8] Mukhaiyar, R., Muskhir, M., \& Dolly, V. P. "Curriculum Evaluation based on AUN-QA Criterion for the Case Study of the Electrical Engineering Vocational and Educational (EEVE) Study Program," In Journal of Physics: Conference Series (Vol. 1387, No. 1, p. 012039). IOP Publishing. Nov. 2019.

[9] Sutrisno dan Suyadi. "Desain Kurikulum Perguruan Tinggi Mengacu Kerangka Kualifikasi Nasional Indonesia," Bandung: PT. Remaja Rosdakarya Offset. 2016

[10] Wina Sanjaya. "Kurikulum dan Pembelajaran, Teori dan Praktik Pengembangan Kurikulum Tingkat Satuan Pendidikan (KTSP)," Jakarta: Kencana. 2008.

[11] Mukhaiyar, R., and Mukhaiyar, Mukhaiyar., "Studi Kajian Pengreorganisasian Kurikulum Prodi-Prodi di Jurusan Teknik Elektro UNP sebagai Acuan Kebijakan bagi Universitas LPTK Lainnya,". Konvensi Nasional Pendidikan Indonesia (KONASPI) VIII. 2016.

[12] Riani Putri, Asti. 'Pengolahan Citra dengan Menggunakan WEb cam Pada Kendaraan Bergerak di Jalan Raya," JIPI (Jurnal Ilmiah Pendidikan Informatika) Volume 1, Nomor 1, Tahun2016: 1-6. 2016.

[13] Sulistiyanti, Sri Ratna., Setyawan, Fx Arinto., \& Kamarudin, Muhammad., Pengolahan Citra Dasar dan Contoh Penerapannya. Yogyakrta: Teknosain. 2016.

[14] Azwar, Syaifuddin., "Metode Penelitian," Yogyakarta: Pustaka Pelajar. 2013. 
[15] Putu Sudira. "Kurikulum dan Pembelajaran Pendidikan dan Pelatihan Vokasi Menyosong Skill Masa Depan," Makalah Pengembangan Kurikulum Politeknik Negeri Bali. Page 1 of 24. Bali: Oktober. 2011.

[16] Mukhaiyar, R., Irfan, D., Frismelly, A., \& Utari, $\mathrm{N}$. "Enrichment in the Electrical Engineering Vocational and Education (EEVE) Study Program by Augmenting the Image Processing Study Course," In Journal of Physics: Conference Series (Vol. 1387, No. 1, p. 012013). IOP Publishing. Nov. 2019.

[17] Mukhaiyar, R., Myori, D. E., \& Utari, N. "Reorganizing the Curriculum of the Study Programs of the Electrical Engineering Fields in Universitas Negeri Padang as Its Eminent Policy," In Journal of Physics: Conference Series (Vol. 1387, No. 1, p. 012043). IOP Publishing. Dec. 2019.

\section{Biodata Penulis}

Nadia Utari, Lahir di Pariaman, 9 Januari 1991. Menyelesaikan S1 Pada Jurusan Pendidikan Teknik Elektronika di Universitas Negeri Padang tahun 2014. Mahasiswa Pascasarjana Pendidikan Teknologi Kejuruan Universitas Negeri Padang tahun 2018 dan juga sebagai Guru paruh waktu di SMK Multi Mekanik Masmur Pekanbaru Riau.

Riki Mukhaiyar, Lahir di Padang, 25 Juni 1978. Menyelesaikan S1 di Universitas Bung Hatta tahun 2000. Menyelesaikan S2 di Institut Teknologi Bandung tahun 2003. Menyelesaikan S3 di University of Newcastle Upon Tyne 2015. Sejak tahun 2008 menjadi dosen tetap di Jurusan Teknik Elektro Fakultas Teknik Universitas Negeri Padang hingga sekarang. 
